\title{
Editor's response
}

\section{Diane Cooper, AHIP}

See end of article for author's affiliation.

I appreciate Mitchell S. Cappell's position, but I strongly disagree with it, for several reasons.

First, the primary or first author is usually felt to be the person who contributed most to the research endeavor. This does not mean who got the money or worked to provide the environment that allowed the research: it is the person who did the most work doing the research. It is virtually impossible to divide work effort into precise degrees, much less to assume it was equally divided, 50/50, among 2 people.

Second, it is subject to subtle and overt coercion. The mentor may say, "Say, mentee, I know you will want a recommendation letter from me. Now, I would like to be co-first author with you. OK?" Even if the mentee did $90 \%$ of the work, she or he is probably going to yield.

Third, the only benefit I see from co-first authors is that it provides a boost to the ego of the co-author, who is apparently gaining credit as if he or she did equal work in the research. Mentors should get gratification in other ways.
DOI: http://dx.doi.org/10.3163/1536-5050.104.4.023

Fourth, first-tier journals now insist that the contribution of each author must be spelled out. Being mentor usually is not sufficient by itself to warrant any authorship. The older concept that the mentor's name is tagged as the last author is no longer used in these journals. The Journal of the Medical Library Association expects named authors to have contributed significantly to the execution of the project and the writing of the manuscript. We often ask for this information and will, indeed, delete authorship of those whose role was only mentor. Their names belong, appropriately, under

"Acknowledgments."

If one person did the most work, that person should have the credit, not have it diluted by some unwritten rule. Two people cannot go through the door at the same time.

\section{AUTHOR'S AFFILIATION}

I. Diane Cooper, AHIP, jmlaeditorbox@gmail.com, Editor-in-Chief, Journal of the Medical Library Association 